\title{
Design and Simulation of a Solar Regulator Based on DC-DC Converters Using a Robust Sliding Mode Controller
}

\author{
Gaga Ahmed, Errahimi Fatima and ES-Sbai Najia \\ Laboratory Renewables Energy and Intelligent Systems, Faculty of Science and Technology, University Sidi Mohamed Ben Abdellah,
} Fez BP 2202, Morocco

Received: June 06, 2015 / Accepted: August 03, 2015 / Published: September 30, 2015.

\begin{abstract}
The MPPT (maximum power point tracking) is one of the most important features of a regulator system that processes the energy produced by a photovoltaic generator. It is necessary, in fact, to design a controller that is able to set the output value of the voltage and ensure the working within the maximum power point. In this paper, we propose the application of the robust sliding mode control technique to a DC-DC buck converter which is combined with a classical P \& O (perturbation and observation) algorithm to enhance the solar system efficiency. Dynamic equations describing the boost converter are derived and a sliding mode controller for a buck converter is designed. It is shown that, this control approach gives good results in terms of robustness toward load and input voltage variations. The effectiveness of the proposed work is verified by the simulation results under PowerSim environment.
\end{abstract}

Key words: Photovoltaic generator, MPPT, DC-DC converter, Buck converter, sliding mode controller, P \& O, PowerSim.

\section{Introduction}

The MPPT (maximum power point tracking) is one of the most important features of a system that processes the energy produced by a photovoltaic generator. It is necessary, in fact, to design a controller that is able to set the value of voltage or current of the generator and always ensure the working within its maximum power point. This point can substantially change its position during the day, essentially due to weather variations, then sunshine and temperature. So, the tracking control of the maximum power point is a complicated problem, to overcome these problems and ensure the high efficiency of the PV system, different solar regulators based on many MPPT strategies have been developed, such as FOCV (fractional open-circuit voltage), FSCC (fractional short-circuit current), fuzzy

Corresponding author: Gaga Ahmed, $\mathrm{PhD}$ student, research fields: energy efficiency, renewable energy and intelligent systems design. E-mail: gaga.ahmad@gmail.com. logic, neural network, $\mathrm{P} \& \mathrm{O}$ (perturbation and observation) and incremental conductance algorithms. These strategies have some disadvantages such as high cost, difficulty, complexity and instability.

To resolve the problems affecting the solar MPPT regulator, especially the stability drawback, we propose a new structure of regulator which is based on double DC-DC converter. The boost converter that allows the nonlinear solar generator to provide maximum power to the photovoltaic terminal, and the buck converter that ensures the voltage regulation at a desired reference point.

The used switched mode DC-DC converters are nonlinear and time variant systems, and do not rule by a linear control theory. The state space averaging method is usually applied for the DC-DC converter characterization. With this approach, an equivalent average model is developed by circuit averaging in a switching case. 
Sliding mode approach for VSS (variable structure systems) offers an alternative way to implement a control action which exploits the inherent variable structure nature of DC-DC converters $[1,2]$. The converters model are presented in state space and controlled in such way to force the system trajectory to remain on a suitable selected surface on the phase space called the sliding surface. The most remarkable feature of sliding mode control is its ability to result in very robust control systems.

\section{DC/DC Converter Modeling}

The switching DC/DC converters are most widely applied in photovoltaic systems as an intermediary between the PV and the load to follow up the MPP (maximum power point). The DC-DC converters are hybrid dynamical systems characterized by both continuous and discrete dynamic behavior. In this section, we present a general modeling approach of DC-DC converters by application of the state space averaging technique of the buck and boost converter for the case of a continuous conduction mode.

Different topologies and different design approaches could be used for DC/DC converters. In this part, two different models of converters are introduced, buck and boost converters. The diagrams in Figs. 1 and 2 show the structure of these converters with the switching period $T$ and duty cycle $d$.

During a period $T$, a switching converter has two working topologies. First, when the switches are closed, the converter model is linear. The state-space equations of the circuit can be written as follows:

$$
\left\{\begin{array}{l}
\dot{x}=A_{1} x+B_{1} u \\
y=C_{1} x+D_{1} u
\end{array}\right.
$$

When the switches are opened, the converters can be modeled by another linear state-space representation written as follows:

$$
\left\{\begin{array}{l}
\dot{x}=A_{2} x+B_{2} u \\
y=C_{2} x+D_{2} u
\end{array}\right.
$$

From the above equation, we can determine the averaged model given by the following state space

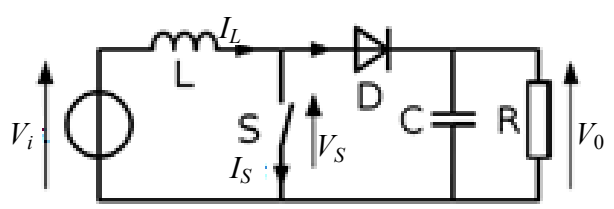

Fig. 1 Equivalent circuit of a boost converter.

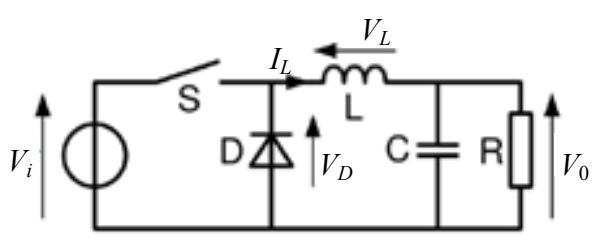

Fig. 2 Equivalent circuit of a buck converter.

equation for an entire switching cycle $T$ :

$$
\left\{\begin{array}{l}
\dot{\tilde{x}}=A_{d} \tilde{x}+B_{d} \tilde{u} \\
\tilde{y}=C_{d} \tilde{x}+D_{d} \tilde{u}
\end{array}\right.
$$

where, the matrices $A_{d}, B_{d}, C_{d}, D_{d}$ are defined as follows:

$$
\begin{array}{r}
\left\{\begin{array}{l}
A_{d}=d A_{1}+(1-d) A_{1} \\
B_{d}=d B_{1}+(1-d) B_{2}
\end{array}\right. \\
\left\{\begin{array}{l}
C_{d}=d C_{1}+(1-d) C_{1} \\
D_{d}=d D_{1}+(1-d) D_{2}
\end{array}\right.
\end{array}
$$

And $\tilde{x}, \tilde{y}$ and $\tilde{u}$ are, respectively the average of $x$, $y$ and $u$ during the switching period $T$. The state space representation can be expressed for these converters as follows:

$$
\left\{\begin{array}{l}
\dot{\tilde{x}}=A_{d} \tilde{x}+B_{d} \tilde{u} \\
V_{0}=C_{d} \tilde{x}+D_{d} \tilde{u}
\end{array}\right.
$$

where:

$$
\tilde{x}=\left(\begin{array}{l}
i_{L} \\
V_{0}
\end{array}\right) \text { and } C_{d}=\left(\begin{array}{l}
0 \\
1
\end{array}\right)^{-1}
$$

\subsection{Buck Converter}

The buck converter is known as the voltage step down and current step up converter [3]. This gives a hint of its typical application of converting its input voltage into a lower output voltage, where the conversion ratio $M=V_{\text {out }} / V_{\text {in }}$ varies with the duty ratio $D$ of the switch [3, 4]. The state space equation of buck converter is as follows:

$$
A_{d}=\left(\begin{array}{cc}
0 & -\frac{1}{L} \\
\frac{1}{C} & -\frac{1}{R C}
\end{array}\right) ; B_{d}=\left(\begin{array}{l}
\frac{d}{L} \\
0
\end{array}\right)
$$


So:

$$
\frac{\mathrm{d} I_{L}}{\mathrm{~d} t}=-\frac{1}{L} \cdot V_{0}+\frac{d}{L} \cdot V_{p v}
$$

2.2 Boost ConverterThe boost converter is also known as the step-up converter. The name implies it is typically application of converting a low input-voltage to a high output voltage, essentially functioning like a reversed buck converter [3, 4]. The state space equation of boost converter is as follows:

$$
A_{d}=\left(\begin{array}{cc}
1 & -\frac{1-d}{L} \\
\frac{1-d}{C} & -\frac{1}{R C}
\end{array}\right) ; B_{d}=\left(\begin{array}{l}
\frac{1}{L} \\
0
\end{array}\right)
$$

So:

$$
\frac{\mathrm{d} I_{L}}{\mathrm{~d} t}=-\frac{1-d}{L} \cdot V_{0}+\frac{1}{L} \cdot V_{p v}
$$

\section{MPPT Technique}

MPPT algorithms are necessary in PV applications because the MPP of a solar panel varies with the irradiation and temperature, so, the use of MPPT algorithm is required in order to obtain the maximum power from a solar array.

The $\mathrm{P} \& \mathrm{O}$ method is one of the most commonly used methods in practice, it is operate by periodically perturbing, i.e., incrementing or decrementing, the array terminal voltage and comparing the PV output power with that of the previous perturbation cycle. If the PV array operating voltage changes and power increases, the control system moves the PV array operating point in that direction. Otherwise, the operating point is moved in the opposite direction, Fig. 3 demonstrates the principle of the P \& O algorithm.

The P \& O algorithm is based on the "hill-climbing" principle, which consists of moving the operation point of the PV array in the direction in which the power increases $[5,6]$. Hill-climbing techniques are the most popular MPPT methods thanks to their ease of implementation and good performance when the irradiation is constant [6]. The advantages of $\mathrm{P} \& \mathrm{O}$

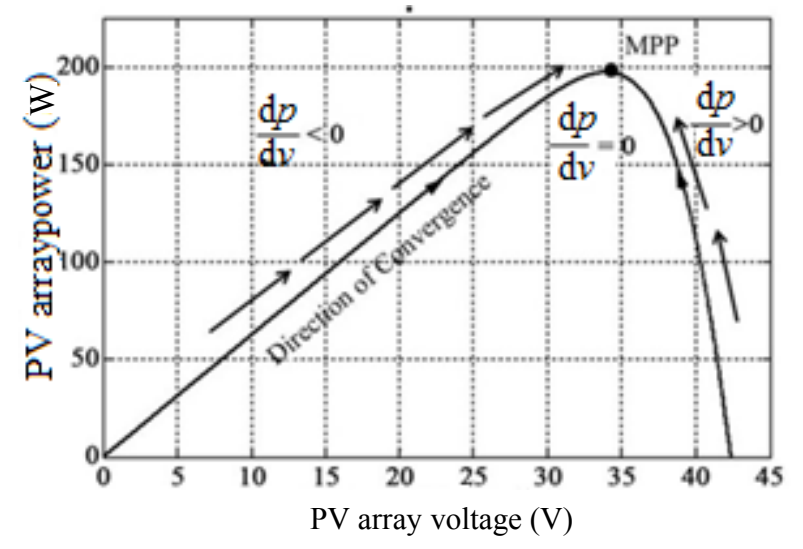

Fig. 3 Principle of $P \& O$ algorithm.

method are the simplicity and low computational power they need. The drawbacks of this technique are mainly two, the main one is that they can easily lose track of the MPP if the irradiation changes rapidly [6-8]. The other handicaps of $\mathrm{P} \& \mathrm{O}$ method are the oscillations of the voltage and current around the MPP in the steady state [7, 9-11].

The Fig. 4 shows the flowchart of the $\mathrm{P} \& \mathrm{O}$ technique.

\section{Sliding Mode Controller}

The SMC (sliding mode control) is naturally well suited for the control of variable structure system, it is a nonlinear control solution for VSC (variable structure

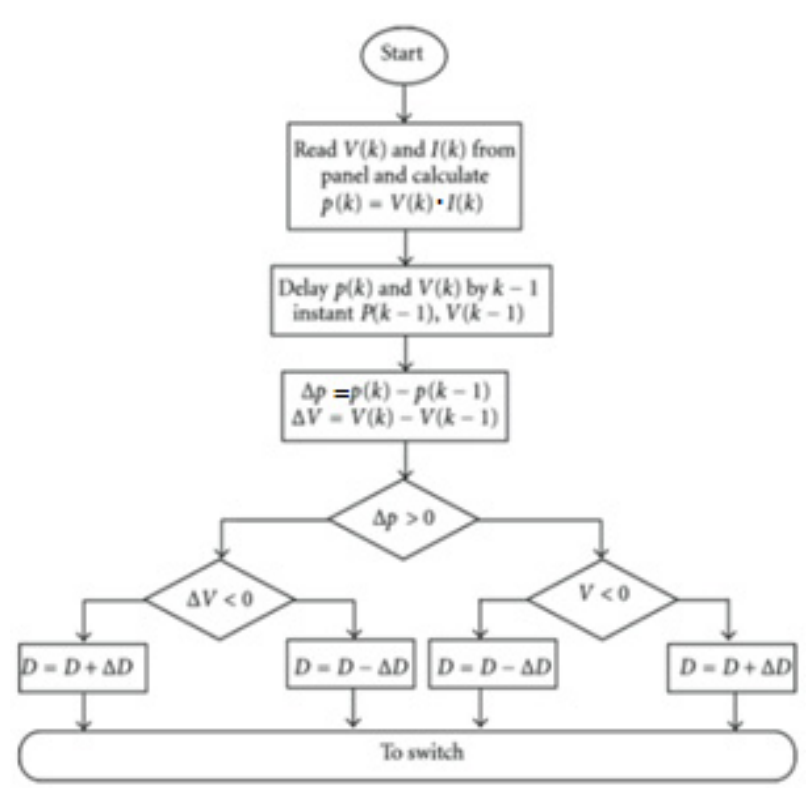

Fig. 4 Flow chart of P \& O MPPT algorithm. 
control) derived from the variable structure system theory.

DC-DC power converters are variable structure systems. So, it is appropriate to apply SM control on these power converters [12]. Moreover, SM control offers excellent large-signal handling capability, which is important for variable structure system, it is known to be robust against modeling inaccuracies and system parameters fluctuations, it was successfully applied to electric motors, robot manipulators, power systems and power converters. Since the design of conventional PWM (pulse-width modulation) controllers is small-signal based, the converters being controlled operate optimally only for a specific condition [13] and often fail to perform satisfactorily under large parameter or load variations (i.e., large-signal operating condition) [14-16]. By replacing linear PWM controllers with a nonlinear sliding mode controller, power converters can reach better regulation and high dynamical performance for a varied operating range.

In this part, we will present the general principle of the SMC and the controller design principle. First, let us consider the nonlinear system represented by the following state equation:

$$
\dot{x}=f(x, t)+g(x, t) u(t)
$$

where, $x$ is n-dimensional column state vector, $f$ and $g$ are dimensional continuous functions in $x, u$ and $t$ vector fields, $u$ is the control input. For the considered system the control input is composed by two components a discontinuous component $U_{n}$ and a continuous one $U_{e q}$.

$$
U=U_{n}+U_{e q}
$$

The continuous component insures the motion of the system on the sliding surface whenever the system is on the surface. The equivalent control that maintains the sliding mode satisfies the following condition:

$$
\dot{S}=0
$$

The equivalent control $U_{e q}$ maybe calculated as:

$$
U_{e q}=-\left(\frac{\partial S}{\partial x} g(x, t)\right)^{-1}\left(\frac{\partial S}{\partial t}+\frac{\partial S}{\partial x} f(x, t)\right)
$$

The nonlinear control component brings the system states on to the sliding surface. The nonlinear control component is discontinuous. It would be of the following general form:

$$
U_{n}=\left\{\begin{array}{l}
u^{-}, S<0 \\
u^{+}, S \geq 0
\end{array}\right.
$$

In this work, the SMC will be applied to a buck to ensure the voltage stabilization in the solar regulator terminal.

We consider the following sliding surface where $k$ is the sliding coefficient and $e$ is the output voltage error defined as follows:

$$
S=k e+\dot{e}
$$

where:

$$
e=V_{\text {out }}-V_{\text {ref }}
$$

By considering the mathematical model of the DC-DC Buck converter, the sliding surface can be expressed by the following expression:

$$
S=-\frac{1}{C} i_{L}+\left(\frac{1}{R C}-K\right) V_{\text {out }}+k V_{\text {ref }}
$$

and its derivative is given by:

$$
\begin{aligned}
\dot{S}=\left(\frac{1-k R C}{R C^{2}}\right) & i_{L}+\left(\frac{L-k R L C-R^{2} C}{R^{2} C^{2} L}\right) V_{\text {out }} \\
& -\left(\frac{V_{\text {in }}}{L C}\right) U
\end{aligned}
$$

Now, we consider the positive definite Lyapunov function $V$ defined as follows:

$$
V=\frac{1}{2} S^{2}
$$

The time derivative $\dot{V}$ of $V$ must be negative definite $\dot{V}<0$ to insure the stability of the system and to make sure that the surface $S$ is attractive. Such condition leads to the following inequality:

$$
S \dot{S}=S\left(-\frac{\dot{V}_{l n}}{L C} U_{n}\right)<0
$$

To satisfy the above condition, the nonlinear control component can be defined as follows:

$$
U_{n}=\operatorname{sign}(S)
$$

\section{Simulations Results}

Fig. 5 shows the block diagram of the complete solar 


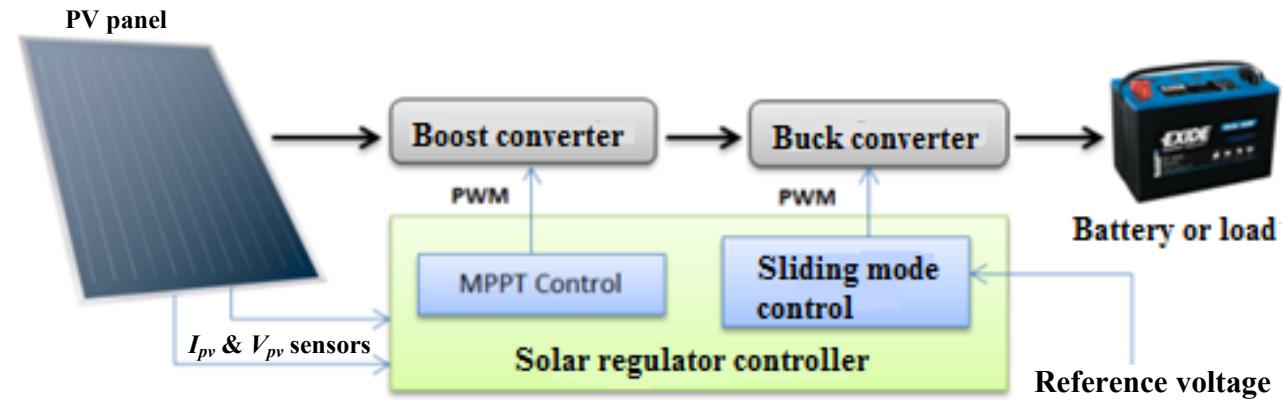

Fig. 5 Block diagram of complete solar regulator.

system regulator based on double DC-DC converter and sliding mode controller.

The circuit of the complete photovoltaic system is simulated under PowerSim environment, the PV system is modeled using solar panel bloc, the MPPT algorithm is modeled using microcontroller bloc and a SMC is modeled using embedded function bloc. Fig. 6 shows that, the PV is connected to a resistive load without MPPT system. The load imposes its own characteristic which is generally different from maximum power point.
The simulation result of the circuit in Fig. 6 shows that, the load cannot extract the available power of the PV terminal (Fig. 7). To overcome this problem, we insert a DC-DC boost converter with variable duty cycle, the interest of this addition is to change the load characteristic which becomes a function of the duty cycle $D$ and allows to move on the solar panel characteristic regardless of the load value. The boost converter is used to raise the input DC voltage to a higher output DC voltage.

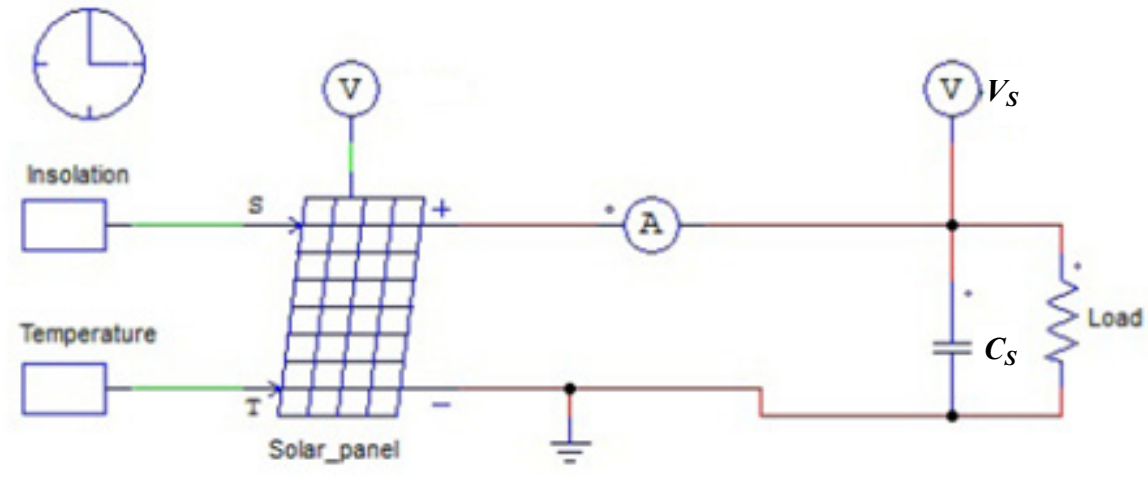

Fig. 6 PV panel without MPPT system.

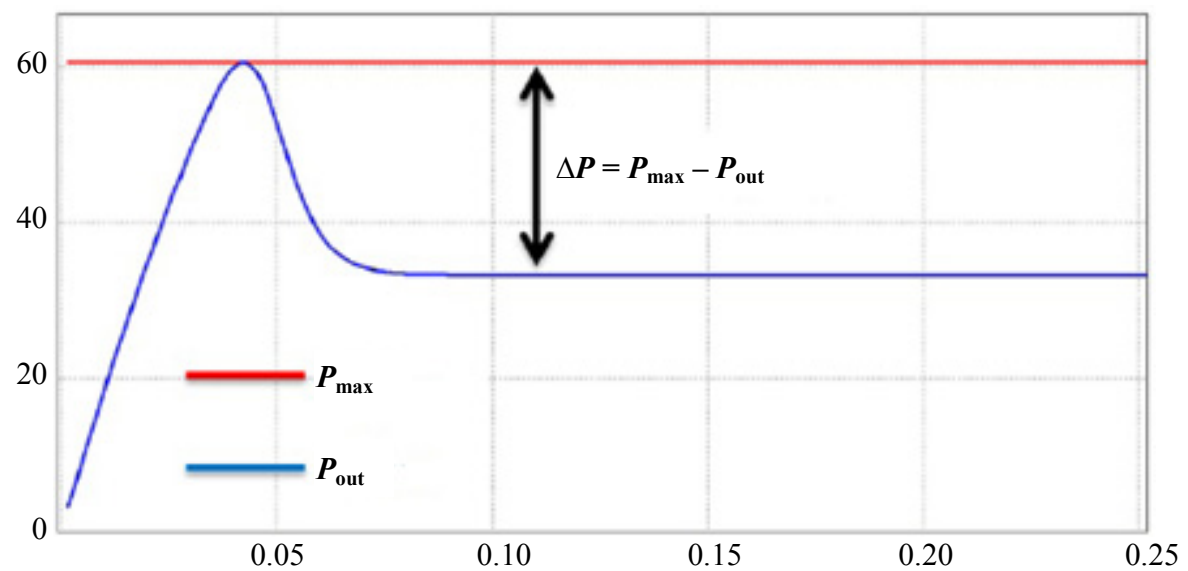

Fig. 7 PV-output power without MPPT system. 
Now, when we can control the output characteristic by varying the duty cycle of the DC-DC boost converter which inserted between the PV panel and load, we need to make this duty cycle automatic, to do this, we must add a microcontroller as a digital processing bloc in which we must implement our MPPT algorithm. Fig. 8 shows the complete circuit diagram based on a PV panel, DC-DC boost converter, load, voltage and current sensors and MPPT controller.

The algorithm shown in Fig. 4 is implemented in the MPPT controller bloc shown in Fig. 8. The following result demonstrates the performance of the MPPT algorithm implementation under irradiance step of 500, 1,000 and $1,500 \mathrm{~W} / \mathrm{m}^{2}$. The MPP values are shown in blue, whereas the real values are shown in red. Fig. 9 illustrates the results of the simulation.

For the SMC voltage regulator which based on a DC-DC converter, we consider the analysis given in the preview part, the proposed SMC was applied to a buck converter characterized by the parameters given in Table 1.

Fig. 10 presents the simulated output voltage by application of a PWM control signal of $50 \%$ duty cycle. The voltage response corresponds to a second order damped system response with an overshoot.

We can notice also that, the load variation affect directly the voltage in the load terminal using open loop control for our buck converter as shown in Fig. 11.

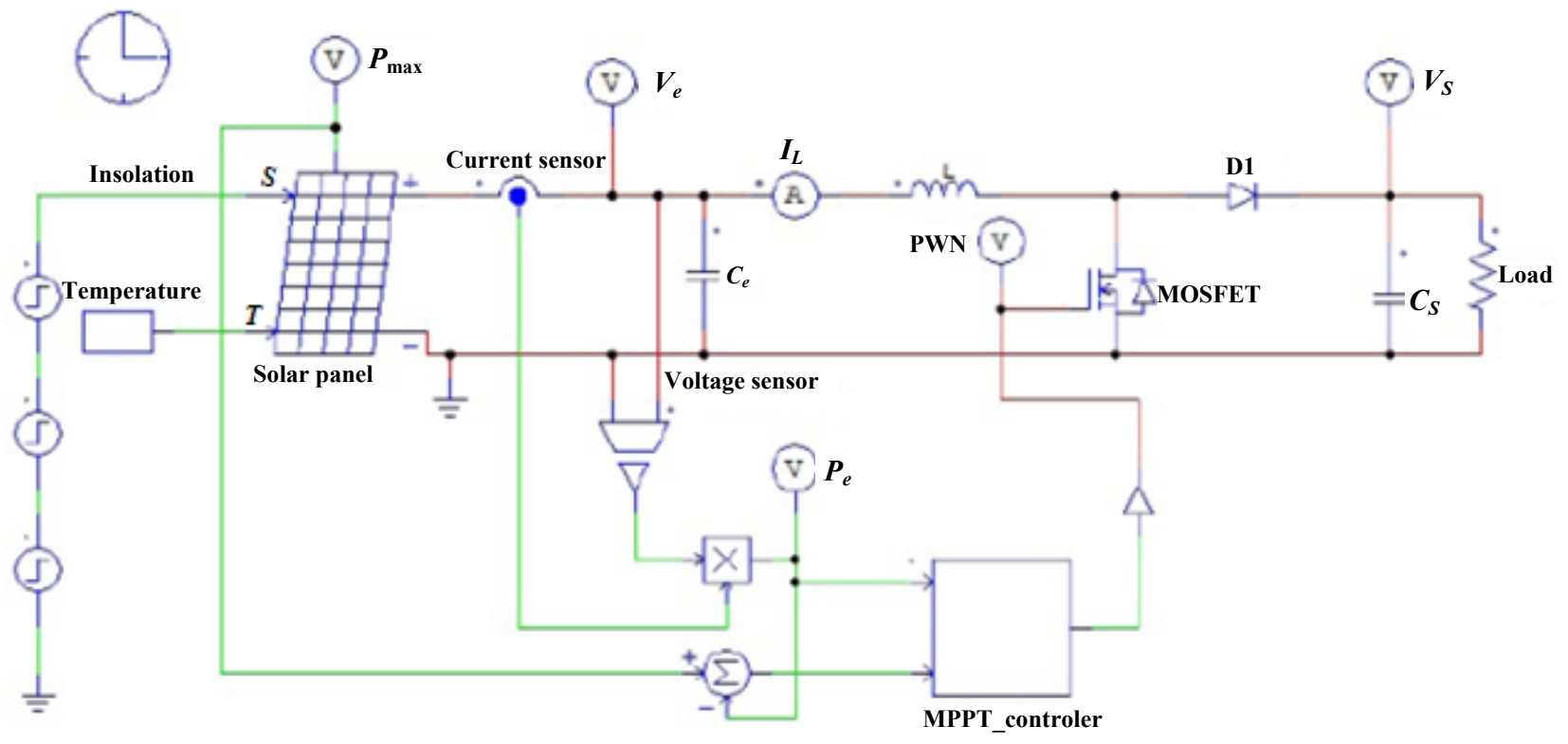

Fig. 8 PV panel with MPPT system.

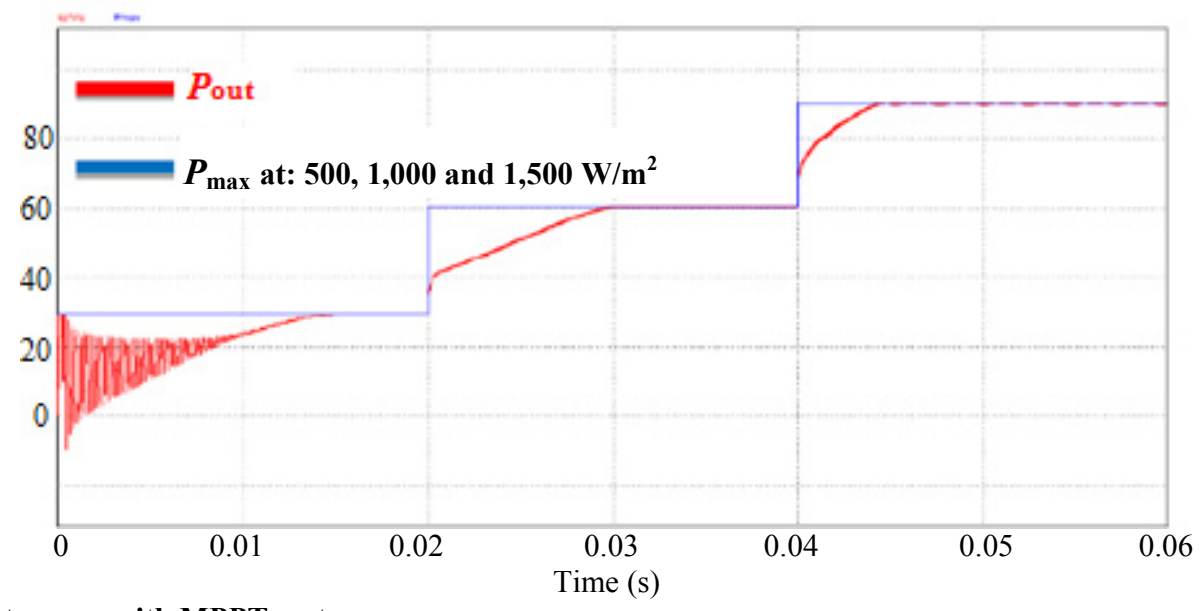

Fig. 9 PV-output power with MPPT system. 
Table 1 Studied buck converter parameters.

\begin{tabular}{ll}
\hline$V_{\text {in }}$ & $17 \mathrm{~V}$ \\
$C$ & $22 \mu \mathrm{F}$ \\
$L$ & $3 \mathrm{mH}$ \\
$R$ & $50 \mathrm{ohm}$ \\
\hline
\end{tabular}

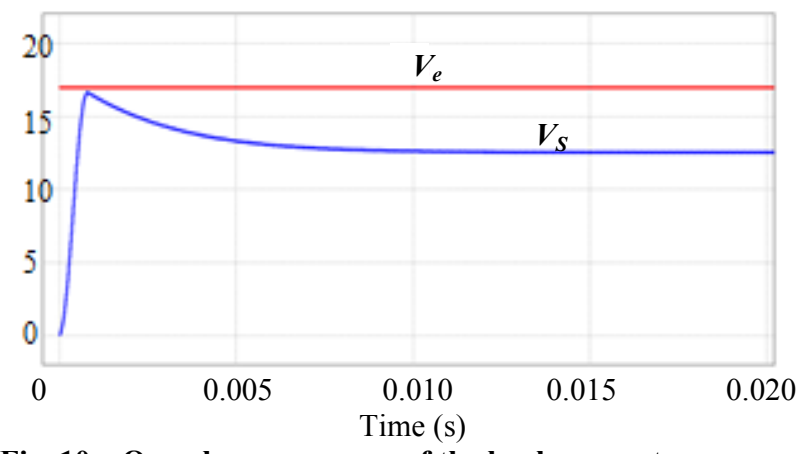

Fig. 10 Open loop responses of the buck converter.

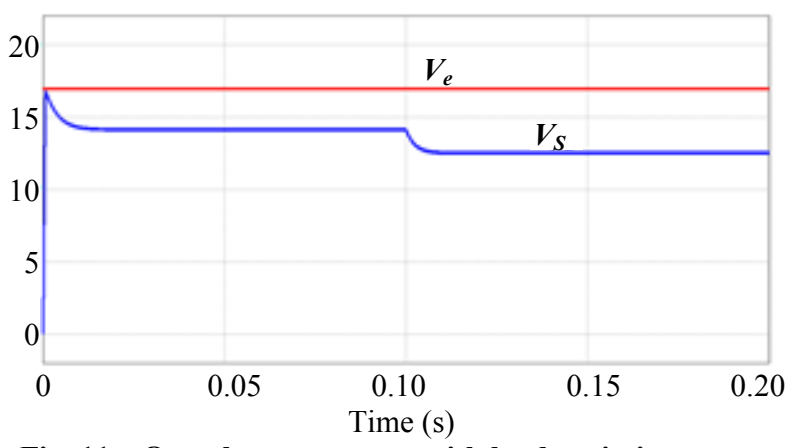

Fig. 11 Open loop responses with load variation.
To resolve this problem, we propose a complete SMC presented in Fig. 12.

Fig. 13 presents the obtained result by application of the proposed SMC to the studied controller for a $7.5 \mathrm{~V}$ for voltage reference. We can see clearly that, the observed voltage overshoot obtained on the open-loop response disappeared by application of the SMC.

The SMC is tested also for the case of the load and input voltage variation. Fig. 14 presents the obtained results for the case of the variation of the load resistance from $100 \Omega$ to $500 \Omega$ at $0.1 \mathrm{~s}$ and also three steps of input voltage variation. It is clear that, this perturbation is quickly rejected because the output voltage attends rapidly to the reference voltage.

Fig. 14 shows the robustness, accuracy and stability of the applied SMC.

\section{Conclusions}

This paper presents the MPPT voltage regulator for solar systems, the simulation of both, MPPT P \& O algorithm and sliding mode controlled DC-DC buck converter are presented in this study. The proposed control schemes are robust with respect to load and

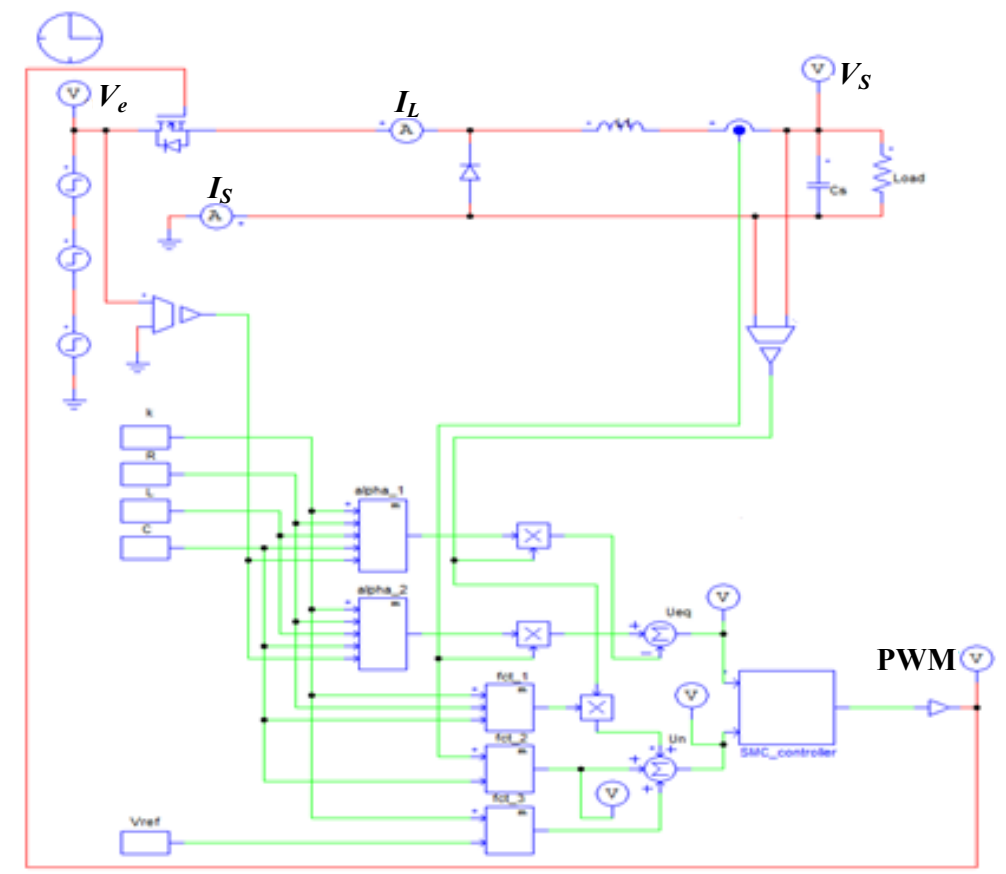

Fig. 12 SMC for buck converter. 


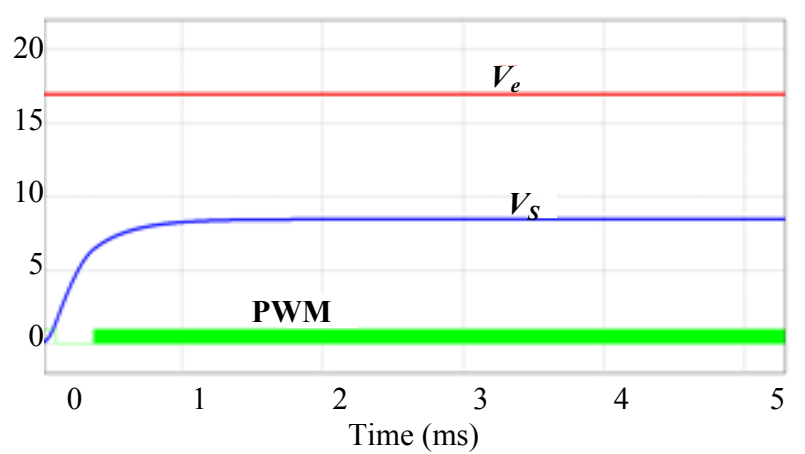

Fig. 13 Application of the SMC to the studied buck converter.

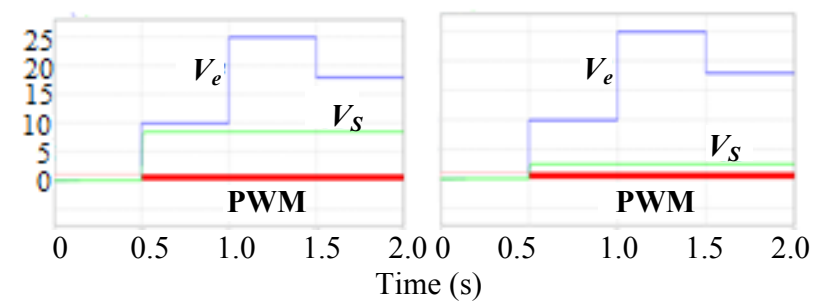

Fig. 14 Output voltage evolution by application of the SMC for the variation of the input voltage $\left(V_{r e f}=2.5 \mathrm{~V}, V_{\text {ref }}=8.5 \mathrm{~V}\right)$.

input voltage step variations. The simulation results show the validity of the sliding mode controller for buck converter model and the robustness of this control technique against change in load and supply parameter.

The proposed system offers a powerful ability which has several advantages such as stability even supply and load variation, robustness and good dynamic behavior.

With additional development, the proposed integrated system will be widely applied to intelligent solar system control. Experimental control projects using FPGA (field programmable gate array) for hardware implementation is our next research effort.

\section{References}

[1] Utkin, V. I. 1978. Sliding Modes and Their Application in Variable Structure Systems. Moscow: MIR Publishers.

[2] Mattavelli, P., Rossetto, L., Spiazzi, G., and Tenti, P. 1993. "Sliding Mode Control of SEPIC Converters." In Proceedings of the ESPC (European Space Power Conferences), 173-8.

[3] Knopf, H. 1999. "Analysis, Simulation, and Evaluation of Maximum Power Point Tracking (MPPT) Methods for a Solar Power Vehicle." M.S. thesis, Portland State University.
[4] Ustun, T. S., and Mekhilef, S. 2010. "Effects of a Static Synchronous Series Compensator (SSSC) Based on Soft Switching 48 Pulse PWM Inverter on the Power Demand from the Grid." Journal of Power Electronics 10 (1): 85-90.

[5] Nguyen, T. L., and Low, K. S. 2010. "A Global Maximum Power Point Tracking Scheme Employing DIRECT Search Algorithm for Photovoltaic Systems." IEEE Transactions on Industrial Electronics 57 (10): 3456-67.

[6] Sera, D., Kerekes, T., Teodorescu, R., and Blaabjerg, F. 2006. "Improved MPPT Algorithms for Rapidly Changing Environmental Conditions." In Proceedings of the 12th International Conference on Power Electronics and Motion Control, 1614-9.

[7] Femia, N., Petrone, G., Spagnuolo, G., and Vitelli, M. 2004. "Optimizing Sampling Rate of P \& O MPPT Technique." In Proceeding of the IEEE PESC (Power Electronics Specialists Conference), 1945-9.

[8] Hussein, K. H., Muta, I., Hoshino, T., and Osakada, M. 1995. "Maximum Photovoltaic Power Tracking: an Algorithm for Rapidly Changing Atmospheric Conditions." IEEE Proceedings on Generation, Transmission and Distribution 142 (1): 59-64.

[9] Femia, N., Petrone, G., Spagnuolo, G., and Vitelli, M. 2005. "Optimization of Perturb and Observe Maximum Power Point Tracking Method.” IEEE Transactions on Power Electronics 20 (4): 963-73.

[10] Zhang, C., Zhao, D., Wang, J., and Chen, G. 2009. “A Modified MPPT Method with Variable Perturbation Step for Photovoltaic System." In Proceedings of the Power Electronics and Motion Control Conference, 2096-9.

[11] Xiao, W., and Dunford, W. G. 2004. "A Modified Adaptive Hill Climbing MPPT Method for Photovoltaic Power Systems." In Proceedings of the IEEE PESC, 1957-63.

[12] Venkataramanan, R. 1986. "Sliding Mode Control of Power Converters." Ph.D. thesis, California Institute of Technology.

[13] Middlebrook, R. D., and Cuk, S. 1976. "A General Unified Approach to Modeling Switching Power Converter Stages." In Proceedings of the IEEE Power Electronics Specialists Conference Record, 18-34.

[14] Forsyth, A. J., and Mollow, S. V. 1998. "Modelling and Control of DC-DC Converters." IEEE Power Engineering Journal 12 (5): 229-36.

[15] Kassakian, J. G., Schlecht, M. F., and Verghese, G. C. 1992. Principles of Power Electronics. Reading, MA: Addison-Wesley.

[16] Mitchell, D. M. 1998. DC-DC Switching Regulator Analysis. New York: Mc-Graw Hill. 